\title{
Ring assembly of silica nanospheres mediated by amphiphilic block copolymers with oxyethylene moieties
}

\author{
Shujun Zhou ${ }^{1,3}$, Yukari Oda ${ }^{2,4}$, Atsushi Shimojima ${ }^{1,5}$, Tatsuya Okubo ${ }^{1}$, Sadahito Aoshima ${ }^{2}$ and \\ Ayae Sugawara-Narutaki ${ }^{1,6}$
}

\begin{abstract}
Silica nanospheres (SNSs) of ca. $15 \mathrm{~nm}$ in diameter assemble into nanoring structures with the aid of amphiphilic block copolymers containing the oxyethylene side chains poly[(2-ethoxyethyl vinyl ether)-block-(2-methoxyethyl vinyl ether)] [poly(EOVE$b$-MOVE)]. Cryo-transmission electron microscope observation confirms that the ring assembly of SNSs occurs in the liquid phase. The SNSs favorably assemble into ring-like nanostructures in the presence of $1-2 \mathrm{wt} \% \mathrm{EOVE}_{100}-b-\mathrm{MOVE}_{310}$ at $\mathrm{pH} \sim 7.8$ and $45^{\circ} \mathrm{C}$. Irregular aggregates of SNSs form at $60^{\circ} \mathrm{C}$, most likely because of the hydrophobic collapse of the thermoresponsive block copolymer. A series of poly(EOVE- $b$-MOVE) with varying block lengths successfully induce the ring assembly of SNSs, whereas a random copolymer fails, indicating that the polymer's molecular structure critically affects the assembly mode of SNSs. Interestingly, SNSs of a larger size $(\mathrm{ca} .30 \mathrm{~nm})$ assemble one-dimensionally into chain-like nanostructures in the presence of $\mathrm{EOVE}_{100}-b-\mathrm{MOVE}_{310}$
\end{abstract}

Polymer Journal (2015) 47, 128-135; doi:10.1038/pj.2014.115; published online 10 December 2014

\section{INTRODUCTION}

The self-assembly of colloidal nanoparticles (NPs) has attracted a great deal of attention for its fundamental scientific interest and technological significance in the fabrication of functional NP arrays. ${ }^{1}$ Among the assembled structures of NPs, NP rings are of interest because of their unique electronic, ${ }^{2}$ magnetic ${ }^{3}$ and optical properties ${ }^{4}$, leading to applications in display, ${ }^{5}$ data storage, ${ }^{6}$ electronic resonators ${ }^{7}$ and spintronic devices, ${ }^{2}$ among others. NP rings as two-dimensional nanostructures are often obtained by drying a suspension of NPs on solid substrates through the evaporation-driven hole formation ${ }^{8}$ and Marangoni flow, ${ }^{9}$ but the obtained ring structures are large, measuring up to several micrometers. Smaller ring structures can be prepared by using templates, such as lithographic patterns, ${ }^{10}$ microspheres, ${ }^{11}$ droplets $^{4,5}$ and bubbles, ${ }^{12,13}$ during the solvent evaporation or liquid flow processes. The above methods are substrate-dependent, therefore limiting applications of the resulting ring structures. The liquid-phase self-assembly approach is highly attractive from a practical standpoint because it can provide free-standing ring nanostructures. Many studies have focused on the ring assembly of magnetic NPs such as Co, ${ }^{14} \mathrm{Ni}-$ $\mathrm{Co}^{15}$ and magnetite, ${ }^{16,17}$ which have anisotropic dipole interactions that drive ring assembly. Magnetic nanorings can be easily obtained through the flux-closure of magnetic NPs. ${ }^{16,18} \mathrm{Au}$ nanorings have been frequently studied for their plasmonic property. The surface of $\mathrm{Au}$ NPs have been functionalized with amine and carboxyl groups at opposite ends ${ }^{19}$ or with DNA molecules ${ }^{20}$ to induce directional coupling between $\mathrm{Au}$ NPs. Ligand-stabilized $\mathrm{Au}$ NPs have been assembled to form ring structures through electrostatic interactions with a disk-shaped viral protein template. ${ }^{21}$ However, the ring assembly of NPs in liquid phase without obvious anisotropic interactions or template is generally a challenging task.

Silica NPs with an amorphous nature and spherical shape are typical isotropic NPs. Silica nanospheres (SNSs), synthesized in the tetraethyl orthosilicate-water biphasic system with L-lysine as the base catalyst, are ideal model NPs for self-assembly in the liquid phase because they have monodisperse size distributions, colloidal stability and sizes that can be controlled to within $15-200 \mathrm{~nm} .^{22}$ We have previously reported the one-dimensional (1D) chain-like structures obtained from SNSs in the liquid phase mediated by the amphiphilic block copolymers PEOPPO-PEO, which consist of poly(ethylene oxide) (PEO) and poly (propylene oxide) (PPO). ${ }^{23,24}$ The polymers affect the interactions among SNSs by adsorbing to the SNS surface via hydrogen bonding between the ether oxygen and silanol groups. ${ }^{23,24}$ The $1 \mathrm{D}$ chain-like

${ }^{1}$ Department of Chemical System Engineering, The University of Tokyo, Tokyo, Japan and ${ }^{2}$ Department of Macromolecular Science, Osaka University, Osaka, Japan

${ }^{3}$ Current Address: School of Materials Science and Engineering, Shanghai Jiao Tong University, Shanghai, China

${ }^{4}$ Current Address: Department of Applied Chemistry, Kyushu University, Fukuoka, Japan

${ }^{5}$ Current Address: Department of Applied Chemistry, Waseda University, Tokyo, Japan

${ }^{6}$ Current Address: Department of Crystalline Materials Science, Nagoya University, Nagoya, Japan

Correspondence: Professor S Aoshima, Department of Macromolecular Science, Osaka University, Machikaneyama, Toyonaka, Osaka 560-0043, Japan.

E-mail: aoshima@chem.sci.osaka-u.ac.jp

or Professor A Sugawara-Narutaki, Department of Crystalline Materials Science, Nagoya University, Furo-cho, Chikusa-ku, Nagoya 464-8603, Japan.

E-mail: ayae@apchem.nagoya-u.ac.jp

Received 8 August 2014; revised 14 October 2014; accepted 15 October 2014; published online 10 December 2014 
structure is achieved when the electrostatic repulsion, steric repulsion and hydrophobic attraction between the SNSs with the surfaceadsorbed polymers are properly balanced. ${ }^{24}$ In brief, the SNSs approach each other owing to weakened electrostatic repulsion at a specific $\mathrm{pH}$ and then attach to form a dimer; meanwhile, the surface-adsorbed amphiphilic polymers rearrange to cause steric crowding at the neck of the dimer. The steric crowding is believed to suppress lateral aggregation and favor the subsequent attachment of an SNS to the end of the dimer, leading to 1D chain-like structures. ${ }^{24}$ Block copolymers in colloidal systems generally introduce a wealth of interactions, such as steric, depletion and hydrophobic interactions, ${ }^{25}$ which can be exploited to manipulate NP assembly. ${ }^{26-28}$ The polymermediated NP assembly strategy has considerable potential in the fabrication of novel assembled nanostructures through the specific control of the interactions among isotropic NPs.

The assembled structure of SNSs, a result of well-balanced interparticle interactions in the presence of block copolymers, should be critically influenced by the polymer structure, which remains largely unexplored. Here, we report that the 'fusion' of SNSs with a tailor-made block copolymer leads to a novel assembled nanostructure. SNSs assemble into ring nanostructures in the liquid phase with the aid of amphiphilic block copolymers consisting of 2-ethoxyethyl vinyl ether (EOVE) and 2-methoxyethyl vinyl ether (MOVE) units (poly(EOVE- $b$-MOVE), Figure 1$)$. The poly(EOVE- $b$-MOVE)s are chosen for the following reasons. First, they interact with the SNS surface through hydrogen bonding between the oxyethylene side chains and silanol groups at the silica surface. Their molecular configuration on the SNS surface is likely to be different from that of the PEO-PPO-PEOs, which adsorb to the SNS through their main chains, thus, a different mode of SNS assembly can be expected. Second, poly(EOVE- $b$-MOVE)s are amphiphilic at mild temperatures $\left(20-60^{\circ} \mathrm{C}\right)$ because of the thermosensitive nature of the EOVE and MOVE units. ${ }^{29,30}$ The polymer amphiphile-derived interactions, such as steric repulsion and hydrophobic attraction, can be fully exploited to promote SNS assembly at a mild temperature. Finally, block lengths of the poly(EOVE- $b$-MOVE)s can be selectively and finely controlled through living cationic polymerization, ${ }^{29-31}$ which enables systematic investigations of the SNS assembly mediated by these polymers.

\section{EXPERIMENTAL PROCEDURE}

\section{Materials}

Tetraethyl orthosilicate (TEOS) was purchased from Tokyo Chemical Industry Co., Ltd., Tokyo, Japan. L-lysine was purchased from Wako Pure Chemical Industries, Ltd., Tokyo, Japan. The purchased chemicals were used without further purification. Deionized water was used as the solvent in all experiments. EOVE and MOVE (Maruzen Petrochemical Co., Ltd., Tokyo, Japan) were washed with $10 \%$ aqueous sodium hydroxide and then with water, dried overnight over potassium hydroxide pellets and distilled over calcium hydride and then metallic sodium. 1,4-Dioxane (Wako Pure Chemical Industries; $>99.5 \%$ ) was distilled over calcium hydride and then lithium aluminum

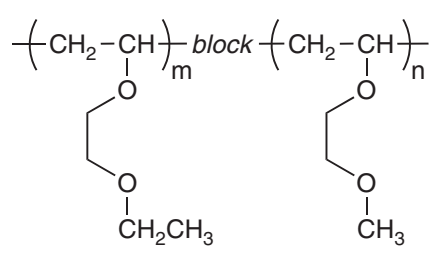

Figure 1 Molecular structure of poly(EOVE- $b-\mathrm{MOVE})$. hydride. 1-(Isobutoxy)ethyl acetate $\left(\mathrm{CH}_{3} \mathrm{CH}(\mathrm{O} i \mathrm{Bu}) \mathrm{OCOCH}_{3}\right)$ was prepared from isobutyl vinyl ether (Tokyo Chemical Industry) and acetic acid ${ }^{31}$ and was distilled twice over calcium hydride under reduced pressure. Toluene (Wako Pure Chemical Industries; 99.5\%) was dried by passage through solvent purification columns (Glass Contour, Pure Process Technology, Nashua, NH, USA) and distilled over metallic sodium. Commercial $\mathrm{Et}_{1.5} \mathrm{AlCl}_{1.5}$ (Nippon Aluminum Alkyls, Ltd., Osaka, Japan; $1.0 \mathrm{M}$ solution in toluene) was used without further purification. All reagents for polymerization, except for toluene, were stored in brown ampules under dry nitrogen.

\section{Preparation of an SNS colloidal suspension}

A colloidal suspension containing SNSs of $15 \mathrm{~nm}$ in diameter was prepared as previously reported. ${ }^{22}$ Typically, L-lysine $(0.037 \mathrm{~g})$ was dissolved in water $(34.80 \mathrm{~g})$ and then TEOS $(2.60 \mathrm{~g})$ was added. The mixture was allowed to react at $60^{\circ} \mathrm{C}$ for $24 \mathrm{~h}$, using a water bath with magnetic stirring at $500 \mathrm{rpm}$. Finally, a homogeneous and optically clear suspension of $\mathrm{SNSs}\left(2 \mathrm{wt} \% \mathrm{SiO}_{2}\right.$, $\mathrm{pH} \sim 9.4$ ) was obtained. Colloidal suspension of SNSs of ca. $30 \mathrm{~nm}$ in diameter was prepared via the seed-regrowth method. In brief, the as-prepared suspension of $15 \mathrm{~nm}$-SNSs $(6.86 \mathrm{~g})$ was added into a lysine aqueous solution (lysine $29 \mathrm{mg}$, water $27.44 \mathrm{~g}$ ), followed by the addition of TEOS $(2.05 \mathrm{~g})$. The mixture was allowed to react at $60^{\circ} \mathrm{C}$ for $24 \mathrm{~h}$ using a water bath with magnetic stirring at $500 \mathrm{rpm}$, yielding a colloidal suspension of SNSs $\left(2 \mathrm{wt} \% \mathrm{SiO}_{2}, \mathrm{pH}\right.$ $\sim 9.3$ ) of $30 \mathrm{~nm}$ in diameter.

\section{Polymer synthesis and analysis}

A series of block and random copolymers of EOVE and MOVE were synthesized by base-assisting living cationic polymerization according to previous reports. ${ }^{29-31}$ The following is the polymerization procedure for $\mathrm{EOVE}_{100}-b$ $\mathrm{MOVE}_{310}$ as an example $\left([\mathrm{EOVE}]_{0}=1.0 \mathrm{M},[\mathrm{MOVE}]_{\mathrm{add}}=3.0 \mathrm{M},[1\right.$-(isobutoxy) ethyl acetate $]_{0}=10 \mathrm{mM}, \quad[1,4$-dioxane $]=1.2 \mathrm{M}, \quad\left[\mathrm{Et}_{1.5} \mathrm{AlCl}_{1.5}\right]_{0}=20 \mathrm{mM}$, in toluene at $0{ }^{\circ} \mathrm{C}$ ). A glass tube equipped with a three-way stopcock was dried using a heat gun under dry nitrogen for $10 \mathrm{~min}$ before use. Toluene $(3.3 \mathrm{ml})$, 1,4-dioxane $(0.60 \mathrm{ml})$, EOVE $(0.80 \mathrm{ml})$ and $80 \mathrm{~mm}$ 1-(isobutoxy)ethyl acetate solution in toluene $(0.75 \mathrm{ml})$ were added to the glass tube and cooled to $0{ }^{\circ} \mathrm{C}$. Polymerization was started by the addition of $200 \mathrm{~mm} \mathrm{Et}_{1.5} \mathrm{AlCl}_{1.5}$ solution in toluene $(0.60 \mathrm{ml})$ into the mixture. After $28 \mathrm{~min}$, when the polymerization of EOVE is close to completion, the second monomer, MOVE $(2.1 \mathrm{ml})$, was added to the reaction mixture. After $90 \mathrm{~min}$, the polymerization was terminated with methanol containing a small amount of an aqueous ammonia solution $(0.3 \mathrm{wt}$ $\%)$. The reaction mixture was washed with aqueous $\mathrm{HCl}$ solution to remove any catalyst residue and was neutralized and concentrated under reduced pressure to give the desired polymer, which was then vacuum-dried over $6 \mathrm{~h}$. The composition of EOVE and MOVE was calculated by ${ }^{1} \mathrm{H}$ nuclear magnetic resonance spectroscopy (NMR, JEOL JNM-ECA 500 spectrometer). The number-average molecular weight $\left(M_{\mathrm{n}}\right)$ and the polydispersity index $\left(M_{\mathrm{w}} / M_{\mathrm{n}}\right)$ $\left(M_{\mathrm{w}}\right.$ : weight-average molecular weight) were calculated from gel permeation chromatography curves in chloroform at $40^{\circ} \mathrm{C}$ with respect to 16 polystyrene standards (Tosoh; $M_{\mathrm{n}}=291-1.09 \times 10^{6}, M_{\mathrm{w}} / M_{\mathrm{n}}<1.1$ ). The characterization of the polymers obtained is summarized in Table 1 .

\section{Table 1 Characterization of poly(vinyl ether)s}

\begin{tabular}{|c|c|c|c|c|c|}
\hline \multirow[b]{2}{*}{ Polymer } & & \multicolumn{2}{|c|}{ Degree of polymerization ${ }^{a}$} & \multirow[b]{2}{*}{$M_{\mathrm{n}}^{\mathrm{b}}$} & \multirow[b]{2}{*}{$M_{\mathrm{w}} / M_{\mathrm{n}}^{\mathrm{b}}$} \\
\hline & & EOVE & MOVE & & \\
\hline 1 & EOVE $_{100-b-M O V E} E_{310}$ & 100 (100) & $310(300)$ & 34100 & 1.15 \\
\hline 2 & EOVE $_{100}-b-M_{194}$ & $100(100)$ & $194(200)$ & 28200 & 1.16 \\
\hline 3 & EOVE $_{50}-b-$ MOVE $_{140}$ & $50(50)$ & $140(150)$ & 23200 & 1.11 \\
\hline 4 & EOVE $_{100-r-M^{-}}$ & $100(100)$ & $210(200)$ & 33100 & 1.13 \\
\hline
\end{tabular}

Abbreviations: EOVE, (2-ethoxyethyl vinyl ether); MOVE, (2-methoxyethyl vinyl ether). ${ }^{a}$ Calculated by ${ }^{1} \mathrm{H}$ NMR spectra. The theoretical degree of polymerization based on the feed ${ }^{a}$ Calculated by ${ }^{1} \mathrm{H}$ NMR spectra. The theoretical degree
monomer composition is presented in the parentheses.

betermined by gel permeation chromatography in $\mathrm{CHCl}_{3}$, polystyrene calibration. 


\section{Polymer-mediated assembly of SNSs}

In a typical procedure, poly(EOVE- $b$-MOVE) was dissolved at $2 \mathrm{wt} \%$ in the asprepared SNS suspension at room temperature, yielding a homogeneous polymer-SNS suspension. Subsequently, the $\mathrm{pH}$ value of the suspension was adjusted using $0.01-1 \mathrm{M}$ aqueous $\mathrm{HCl}$ solutions. The suspension was then statically heated at $45^{\circ} \mathrm{C}$ in an oven for several days.

\section{Characterization}

Morphology of the products was observed using a Hitachi S-900 scanning electron microscope (SEM) at an accelerating voltage of $6 \mathrm{kV}$. Silicon wafers were cleaned with Semico Clean 56 (Furuuchi Chemical, Tokyo, Japan) in an ultrasonic bath for $15 \mathrm{~min}$ and then with water for $15 \mathrm{~min}$ at room temperature, followed by rinsing with ethanol and drying in air. All of the samples were diluted 10 times with deionized water and then deposited onto clean silicon wafers by dip-coating at a withdrawal speed of $10 \mathrm{~mm} \mathrm{~min}^{-1}$. Ultraviolet-ozone treatment of the samples was performed to remove any unreacted organic species. To minimize the charging-up of electrons during SEM observation, the samples were sputtered with $\mathrm{Pt}$ in an Ar atmosphere using an ion sputter system (Hitachi E-1030) prior to SEM analysis. For cryotransmission electron microscope (cryo-TEM) observation, a sample was diluted 10 times with deionized water and then dropped on a micro-grid. After making the liquid thin film of the sample on the micro-grid by blotting with filter paper, it was vitrified by rapidly immersing into liquid ethane using an EM CPC cryo-station (Leica Microsystems, Wetzlar, Germany). The vitrified sample was observed using a JEOL $2100 \mathrm{~F}$ TEM operated at $200 \mathrm{kV}$. The temperature of the sample was maintained below $-170{ }^{\circ} \mathrm{C}$ throughout the observation.

\section{RESULTS}

\section{Block copolymerization}

A series of block copolymers [poly(EOVE- $b$-MOVE)s] with varying compositions were prepared using base-assisting living cationic polymerization. ${ }^{29-31}$ The resulting copolymers have narrow molecular weight distributions $\left(M_{\mathrm{w}} / M_{\mathrm{n}} \leqslant 1.16\right)$; the target compositions are shown in Table 1. Block copolymer $\mathbf{1}$ has the highest molecular weight among all polymers. Polymer 2 has the same EOVE block length but a shorter MOVE block length as compared with $\mathbf{1}$. The sizes of both the EOVE and MOVE blocks of polymer 3 are approximately half of that of polymer 1 . The EOVE and MOVE blocks turn from hydrophilic to hydrophobic with increasing temperature at $\sim 20^{\circ} \mathrm{C}$ and $60^{\circ} \mathrm{C}$, respectively. ${ }^{29,30}$ Random copolymer 4 having the similar molecular weight and composition as that of block copolymer 2 was also synthesized.
Polymer-mediated ring assembly of SNSs in the liquid phase The assembly experiments were conducted at $45^{\circ} \mathrm{C}$ to ensure amphiphilicity of the block copolymers. The suspension containing block copolymer 1 (2 wt\%) and SNSs (15 nm, $2 \mathrm{wt} \%)$ at $\mathrm{pH} 7.7$ gains a bluish color after heating at $45^{\circ} \mathrm{C}$, suggesting the occurrence of Rayleigh scattering (Figure 2a). Figure $2 \mathrm{~b}$ is an SEM image of the sample showing ring-like nanostructures composed of the SNSs. The number of SNSs comprising only one ring is mostly $3-5$. The ring-like nanostructures have a size of ca. 30-50 nm, which are compatible sizes to cause Rayleigh scattering. Cryo-TEM observation is conducted to minimize the effects of the drying process and substrate on the sample structure. The cryo-TEM image (Figure 2c) shows ring-like nanostructures similar to those observed with SEM, indicating that the ringlike nanostructures should form in the liquid phase. In addition to closed-ring nanostructures, open rings are also observed.

\section{Effects of polymer concentration, $\mathrm{pH}$ and temperature on the ring assembly of SNSs}

The effect of polymer concentration on ring assembly was examined using block copolymer $\mathbf{1}$ as an example. The polymer-free SNS suspension is colloidally stable at $\mathrm{pH} \sim 7.7$ and $45^{\circ} \mathrm{C} .{ }^{23,24}$ However, the SNS suspensions containing 0.1 and 0.5 wt $\%$ of 1 at $\mathrm{pH} 7.8$ undergo gelation soon after heating at $45^{\circ} \mathrm{C}$. SEM observation of the gel reveals that the SNSs form dense irregular aggregates (Figures 3a and $\mathrm{b}$ ). When the concentration of $\mathbf{1}$ is increased to $1 \mathrm{wt} \%$, the suspension at $\mathrm{pH} 7.8$ remains a homogenous fluid and becomes bluish after heating at $45^{\circ} \mathrm{C}$. SNS nanorings can be observed in the presence of $1 \mathrm{wt} \%$ of polymer 1 (Figure 3c), similar to our observations when using $2 \mathrm{wt} \%$ of 1 (Figure $2 \mathrm{~b}$ ).

The favorable $\mathrm{pH}$ for ring assembly is $\sim 7.8$ with $2 \mathrm{wt} \%$ of 1 at $45^{\circ} \mathrm{C}$ (Figure 4a). The SNSs tend to form three-dimensional clusters rather than rings with decreasing $\mathrm{pH}$ value (Figures $4 \mathrm{~b}$ and $\mathrm{c}$ ). No gelation or phase separation of the suspension is observed even at a lower $\mathrm{pH}$ of $\sim 6$, whereas such phenomena are frequently observed when PEOPPO-PEO block copolymers are used as the mediator. ${ }^{24}$

Raising the temperature to $60^{\circ} \mathrm{C}$ causes the formation of irregular particle aggregates at $\mathrm{pH} 7.8$ and with $2 \mathrm{wt} \%$ of $\mathbf{1}$ (Figure 5), which are the optimal $\mathrm{pH}$ and polymer concentration for the ring assembly of SNSs at $45^{\circ} \mathrm{C}$. At this temperature, 1 should behave as a hydrophobic polymer because both the EOVE and MOVE blocks are hydrophobic at above $60^{\circ} \mathrm{C} .{ }^{29,30}$
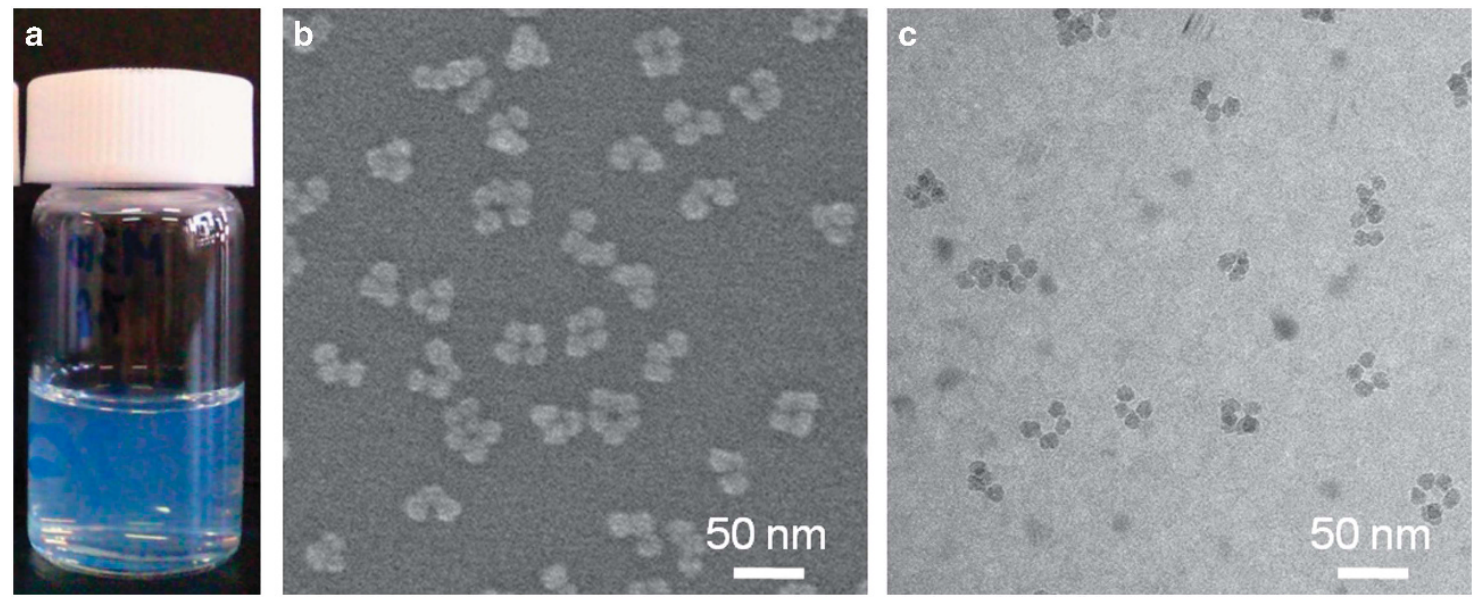

Figure 2 (a) A photograph of the suspension containing 1 (2 wt\%) and SNSs at $\mathrm{pH} 7.7$ after heating at $45^{\circ} \mathrm{C}$, (b) SEM and (c) cryo-TEM images of ring structures obtained from the above suspension. 

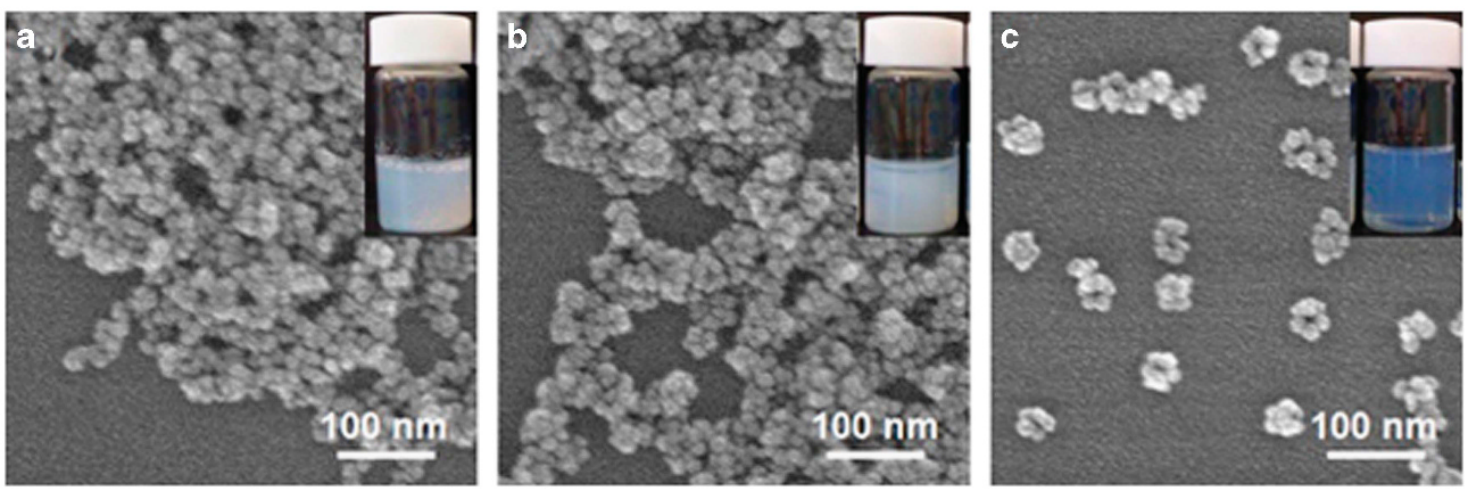

Figure $3 \mathrm{SEM}$ images of the products obtained from the suspensions containing (a) $0.1 \mathrm{wt} \%$, (b) $0.5 \mathrm{wt} \%$ and (c) $1 \mathrm{wt} \%$ of 1 and SNSs at pH 7.8 after heating at $45^{\circ} \mathrm{C}$. The insets in (a), (b) and (c) are digital photos of the corresponding samples.
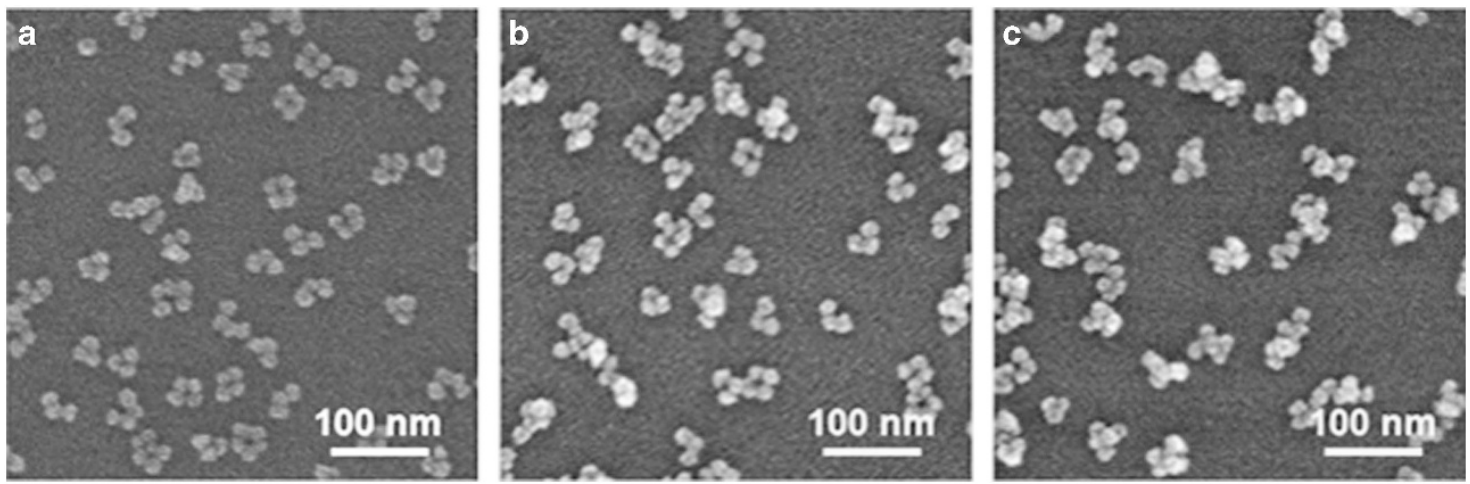

Figure 4 SEM images of the products obtained from the suspensions containing 2 wt\% of 1 and SNSs at (a) $\mathrm{pH} 7.8$, (b) $\mathrm{pH} 7.2$ and (c) $\mathrm{pH} 6.8$ after heating at $45^{\circ} \mathrm{C}$.

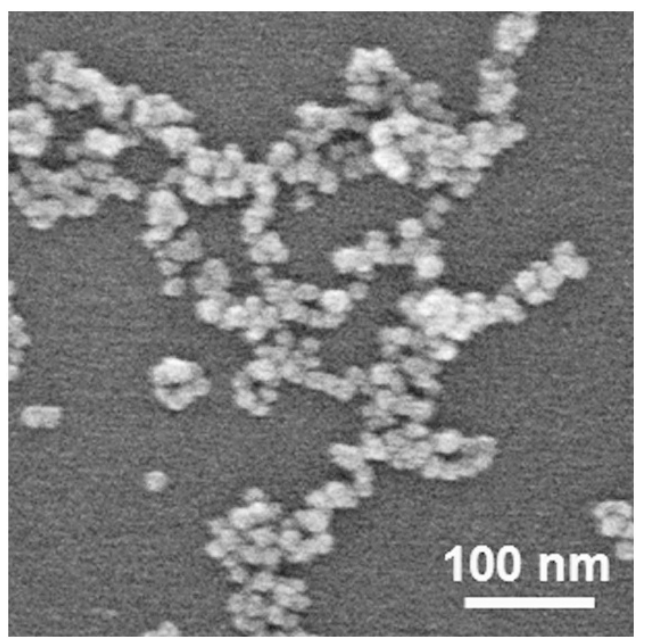

Figure 5 SEM image of the product obtained from the suspension containing 2 wt $\%$ of 1 and SNSs at pH 7.8 after heating at $60^{\circ} \mathrm{C}$.

\section{Formation process of ring-like nanostructures}

The formation process of ring-like nanostructures was examined using SEM observations of the block copolymer 1 (1 wt $\%)$-SNS suspensions at pH 7.8 heated at $45^{\circ} \mathrm{C}$ for different periods of time. SEM images of the products from suspensions heated for $\leqslant 1 \mathrm{~h}$ show many isolated SNSs and few ring-like nanostructures in addition to $1 \mathrm{D}$ chains
(Figures $6 \mathrm{a}-\mathrm{c}$ ). There are small clusters of SNSs on the silicon wafer, which might be caused by the drying process. The appearance of isolated SNSs obviously decreases and ring-like nanostructures emerge after $2-6 \mathrm{~h}$ of heating (Figures 6d-f). Ring-like nanostructures are dominant and the isolated SNSs are negligible after $24 \mathrm{~h}$ of heating (Figure $6 \mathrm{~g}$ ). The ring-like nanostructures remain unchanged after 3 days of heating (Figure $6 \mathrm{~h}$ ).

Effects of polymer structures on the ring assembly of SNSs

The effect of polymer structures on the SNS assembly was investigated at a fixed polymer concentration $(2 \mathrm{wt} \%)$ at $45^{\circ} \mathrm{C}$. Block copolymers 2 and 3 with different block lengths also induce the ring assembly of SNSs. Polymer 2, having the same EOVE length but a shorter MOVE length compared with those of $\mathbf{1}$, gives nanorings at $\mathrm{pH} 7.8$ (Figure 7a), which is similar to the optimal $\mathrm{pH}$ for 1 . Reducing $\mathrm{pH}$ to 7.2 causes the accumulation of nanorings to form larger structures (Figure 7b), which is different from the case with $\mathbf{1}$ where the rings remain isolated. Nanorings are also observed with polymer 3 at $\mathrm{pH} 7.8$ (Figure 7c), but the structure is less well-defined when compared with those obtained with $\mathbf{1}$ or $\mathbf{2}$. Similar to what is observed with polymer 2 , the nanorings tend to accumulate with decreased $\mathrm{pH}$ (Figure 7d). The random copolymer 4 , which has a similar molecular weight and composition as that of block copolymer 2 , does not induce any ring formation. The 4-SNS suspension remains transparent at $\mathrm{pH}$ above

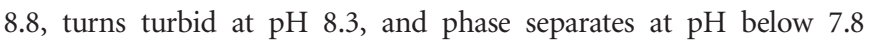
(Figure 8a). SEM images reveal that many SNSs remain isolated at $\mathrm{pH}$ 

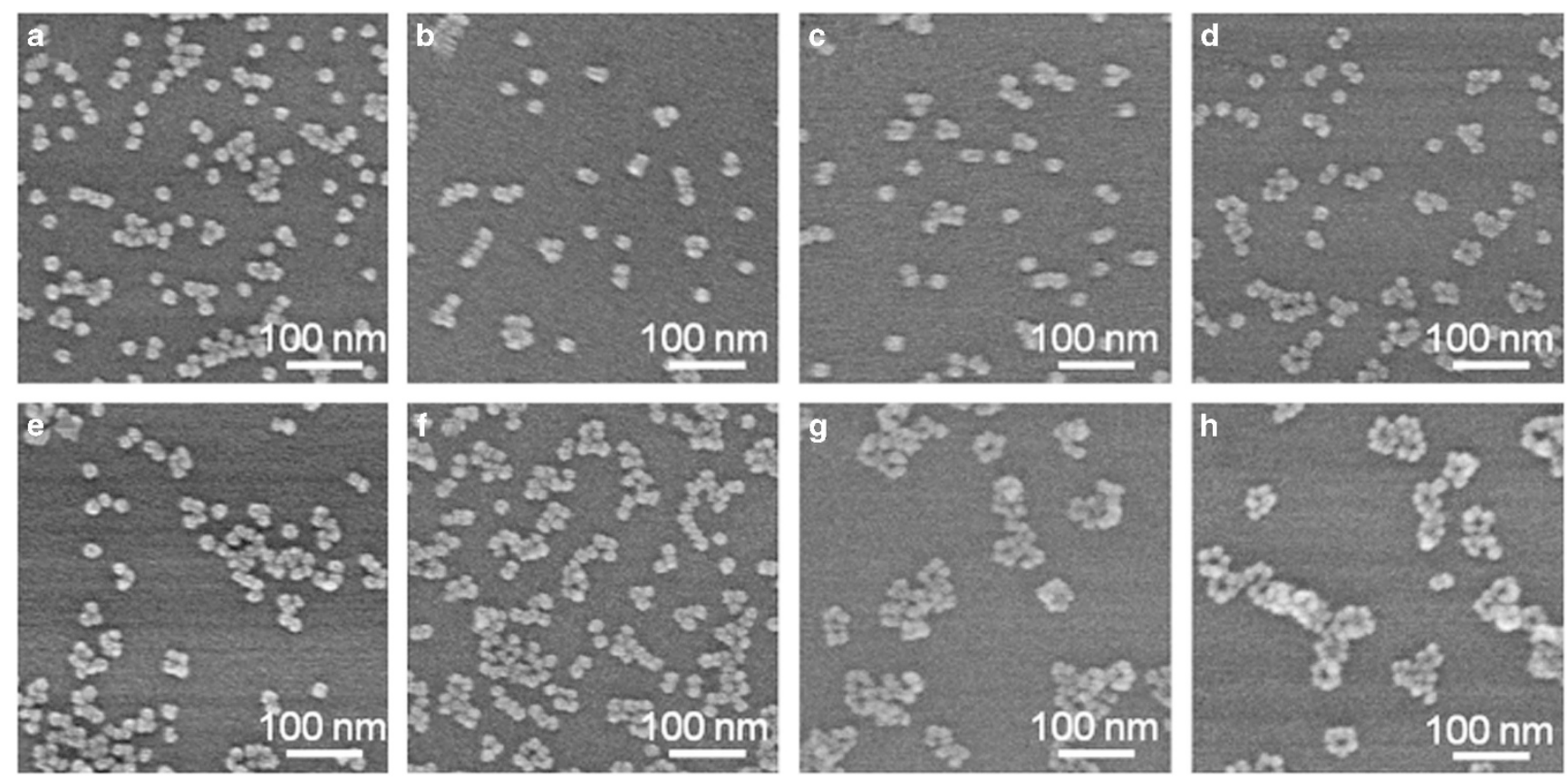

Figure 6 SEM images of the products obtained from the suspension containing 1 wt\% of 1 and SNSs at pH 7.8 (a) before heating and (b-h) after heating at $45^{\circ} \mathrm{C}$ : (b) $0.5 \mathrm{~h}$, (c) $1 \mathrm{~h}$, (d) $2 \mathrm{~h}$, (e) $3 \mathrm{~h}$, (f) $6 \mathrm{~h},(\mathrm{~g}) 24 \mathrm{~h}$ and (h) 3 days.
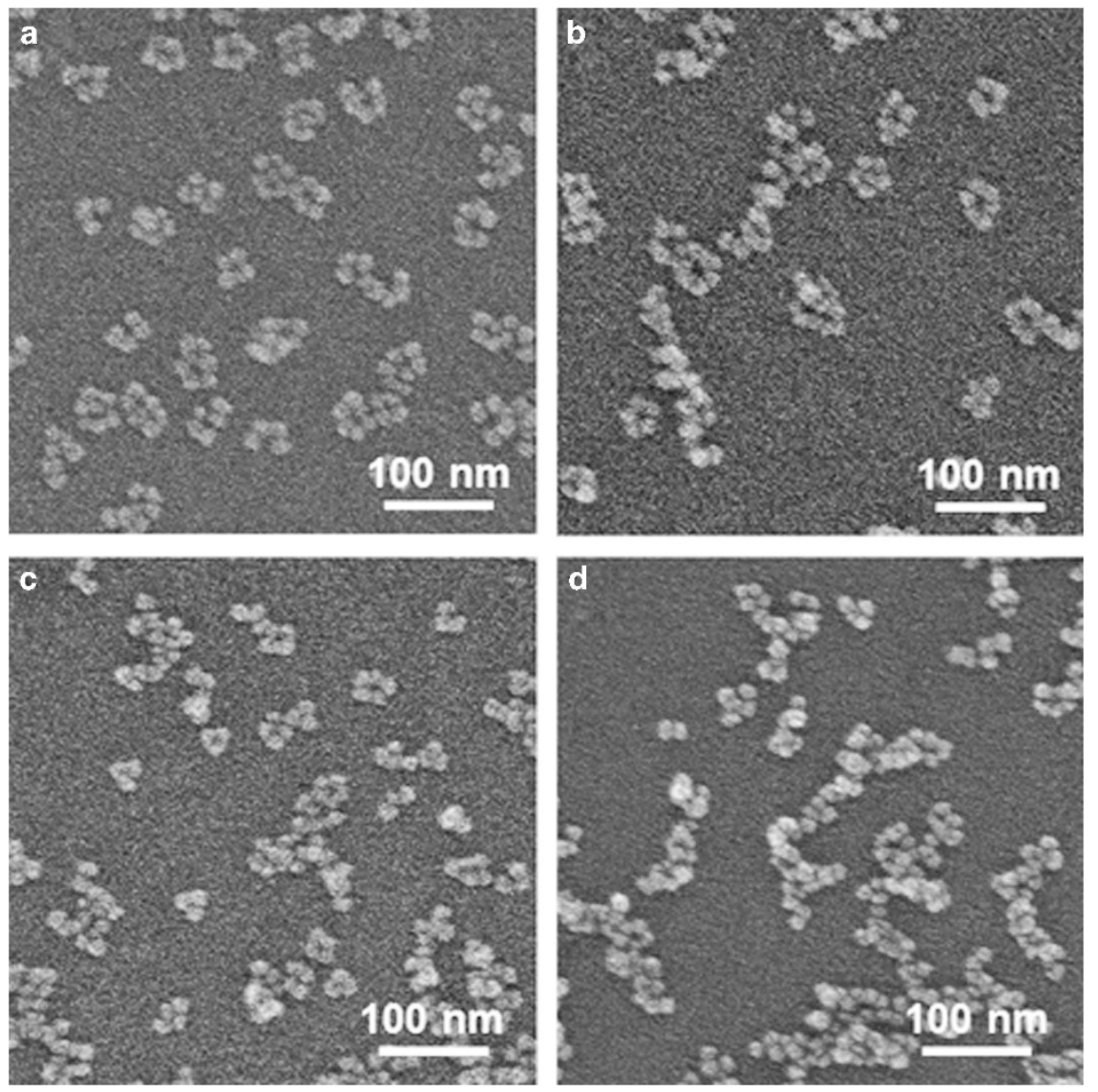

Figure 7 SEM images of the products obtained from the suspensions containing 2 wt $\%$ of 2 and SNSs at (a) $\mathrm{pH} 7.8$ and (b) $\mathrm{pH} 7.2$, and 2 wt\% of $\mathbf{3}$ and SNSs at (c) pH 7.8 and (d) $\mathrm{pH} 7.2$ after heating at $45^{\circ} \mathrm{C}$. 
a
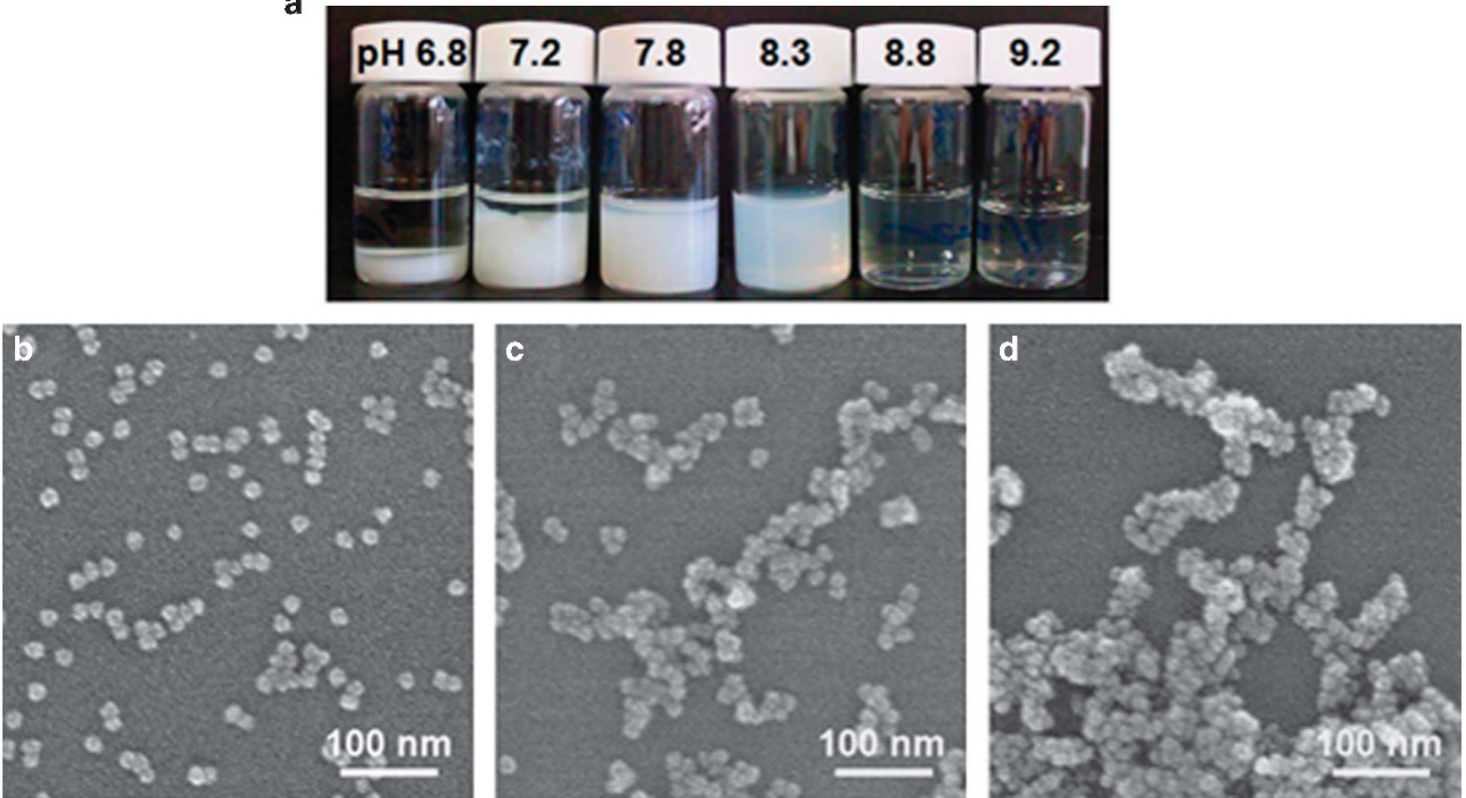

Figure 8 (a) Digital photo of the suspensions containing 2 wt\% of 4 and SNSs within pH 6.8-9.2 after heating at $45^{\circ} \mathrm{C}$ for 7 days. (b-d) SEM images of the products at (b) $\mathrm{pH} 8.8$, (c) $\mathrm{pH} 8.3$ and (d) $\mathrm{pH} 7.8$.

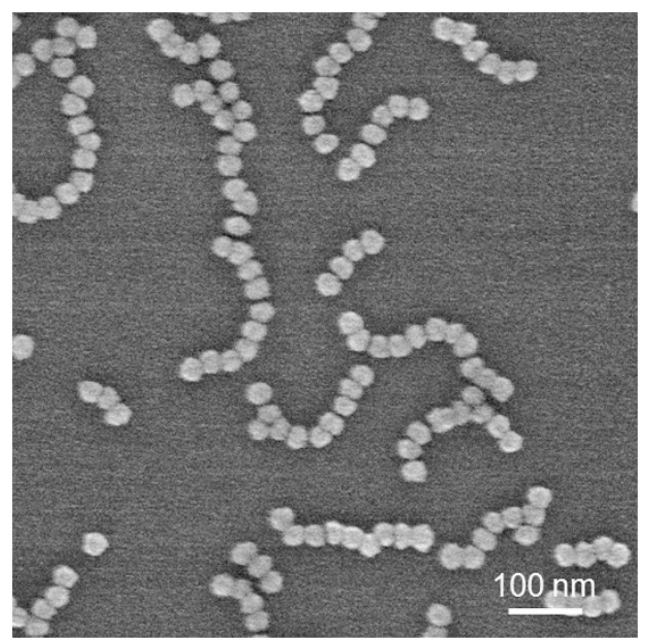

Figure 9 SEM image of the product from the suspension containing SNSs $(30 \mathrm{~nm})$ and $2 \mathrm{wt} \%$ of 1 after heating at $45^{\circ} \mathrm{C}$.

8.8 (Figure $8 \mathrm{~b}$ ) and they formed aggregates at lower $\mathrm{pH}$ values (Figures $8 \mathrm{c}$ and $\mathrm{d}$ ).

\section{D assembly of $30 \mathrm{~nm}-\mathrm{SNSs}$}

Interestingly, it is found that SNSs that are $30 \mathrm{~nm}$ in diameter onedimensionally assemble into chain-like nanostructures in the presence of $2 \mathrm{wt} \%$ of 1 at $\mathrm{pH} 7.7$ and $45^{\circ} \mathrm{C}$ (Figure 9), similar to the phenomena observed when PEO-PPO-PEO block copolymers are used as the mediator. ${ }^{24}$

\section{DISCUSSION}

A detailed study of the ring assembly system mediated by $\mathrm{EOVE}_{100}-b$ $\mathrm{MOVE}_{310}$ (block copolymer 1) shows that specific experimental conditions are required to achieve well-defined nanorings composed of SNSs. At least $1 \mathrm{wt} \%$ of 1 is required against $2 \mathrm{wt} \%$ of SNSs to obtain the nanorings (Figure 3). Lower concentrations of $\mathbf{1}$ ( 0.1 and $0.5 \mathrm{wt} \%$ ) cause random particle aggregation and, consequently, gelation of the suspension. The particle aggregation at low polymer concentrations in polymer - NP colloidal systems is often caused by bridging flocculation, where a polymer molecule simultaneously adsorbs to more than two NPs and causes their aggregation. ${ }^{32}$ This tendency of random aggregation of SNSs at low polymer concentrations was also observed in our previous study using PEO-PPO-PEO block copolymers as the mediator. ${ }^{24}$ An optimal $\mathrm{pH}$ for ring assembly also exists: nanorings composed of SNSs are obtained in high yields at $\mathrm{pH} 7.8$ in the presence of $\mathbf{1}(2 \mathrm{wt} \%)$, whereas clusters of SNSs form at $\mathrm{pH}$ below 7.2 (Figure 4). It is known that colloidal silica

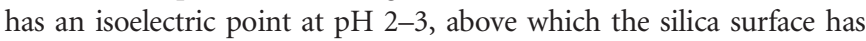
negative $\mathrm{Si}-\mathrm{O}^{-}$groups. ${ }^{33}$ Decreasing the $\mathrm{pH}$ value reduces the number of $\mathrm{Si}_{-} \mathrm{O}^{-}$groups at the silica surface and weakens the electrostatic repulsions among SNSs. In our previous study, the SNSs generally form random aggregates at $\mathrm{pH}$ below 7.0 in the presence of PEO-PPO-PEOs. ${ }^{24}$ By contrast, the SNSs form isolated clusters instead of irregular aggregates at $\mathrm{pH} 6.8$ in the presence of $\mathbf{1}$. We propose that the hydrophilic MOVE block of $\mathbf{1}$ provides considerable steric interactions to suppress the heavy aggregation of SNSs. This hypothesis is supported by the observation of aggregation of SNSs at $\mathrm{pH} \sim 7$ with polymer 2 (Figure $7 \mathrm{~b}$ ), which has a shorter MOVE block than that of 1 . The incubation temperature is also an important factor for the formation of nanorings. Only aggregates of SNSs are obtained with 1 at $60^{\circ} \mathrm{C}$ (Figure 5), at which both the EOVE and MOVE blocks are hydrophobic. Polymer 1 that adsorbs to the SNS surface may hydrophobically interact, inducing aggregation of the SNSs.

A series of EOVE- $b$-MOVE block copolymers (1-3) successfully induce ring assembly of SNSs under similar optimal conditions (polymer concentration $\sim 2 \mathrm{wt} \%, \mathrm{pH} \sim 7.8$ ) (Figure 4 and Figure 7 ), whereas the random copolymer $\mathbf{4}$ fails to give nanorings even within a 
wide $\mathrm{pH}$ range 6.8-9.2 (Figure 8). Here, the inter-particle interactions in play may include electrostatic repulsion, caused by the surface charges of SNSs, and steric repulsion and hydrophobic attractions, induced by the surface-adsorbed amphiphilic polymers. ${ }^{24}$ The suspension containing 4 and SNSs is turbid at $\mathrm{pH} 8.3$, suggesting that the net attractive interaction is stronger in the 4 - SNS system when compared with the systems containing the block copolymers $\mathbf{1}-\mathbf{3}$. These block copolymers adsorb to the SNS surface in such a manner that the hydrophilic MOVE blocks may populate the polymer-water interface, whereas the random copolymer adsorbs to the SNS surface homogeneously with both hydrophobic EOVE and hydrophilic MOVE units distributed at the polymer-water interface. The difference of polymer configurations at the polymer-water interface and the SNS surface may greatly affect the assembly mode of SNSs.

The mechanisms of ring assembly of the SNSs, mediated by poly(EOVE- $b$-MOVE), remain to be clarified. There are two possible routes for the isolated SNSs to assemble into ring structures. One possible route is that the SNSs consecutively attach to each other at a certain angle. However, this route does not explain why only a close ring structure instead of varied open structures (for example, a helix) is produced in this mode. The other possible route is that the SNSs initially assemble into a $1 \mathrm{D}$ chain-like structure, which subsequently bends into a ring structure. The formation of chain-like structures with SNSs of $30 \mathrm{~nm}$ in diameter confirms that the poly(EOVE- $b$ MOVE) is capable of mediating the $1 \mathrm{D} \mathrm{NP}$ assembly, suggesting a relationship between the ring and $1 \mathrm{D}$ assembly. It is likely that the $1 \mathrm{D}$ chains observed at the early stages of ring assembly (Figures $6 a-c$ ) are precursors of the nanorings, and a driving force to achieve an energetically stable configuration forces their bending into the nanorings. The relationship between ring assembly and the percolation phenomena in NP-polymer systems is also worth considering. Here, SNSs form percolated large clusters or networks under specific experimental conditions. Ring-like small clusters might form near the percolation threshold, the value of which varies with the size, conformation and concentration of the polymers. ${ }^{34}$ A more systematic study to understand the mechanisms of ring assembly will be conducted from both chemical and physical perspectives.

\section{CONCLUSION}

Liquid-phase ring assembly of SNSs with a diameter of ca. $15 \mathrm{~nm}$ is achieved using the thermosensitive block copolymers poly(EOVE- $b$ MOVE) as the mediator. A series of block copolymers $\mathrm{EOVE}_{50}-b$ $\mathrm{MOVE}_{140}, \mathrm{EOVE}_{100}-b-\mathrm{MOVE}_{194}$ and $\mathrm{EOVE}_{100}-b-\mathrm{MOVE}_{310}$ promote the ring assembly of $\mathrm{SNSs}$ at $\mathrm{pH} \sim 7.8$. However, the random copolymer $\mathrm{EOVE}_{100^{-}} r-\mathrm{MOVE}_{210}$ fails to induce ring assembly, suggesting that the primary structure of polymer chains critically affects the assembly of SNSs. Using $\mathrm{EOVE}_{100}-b-\mathrm{MOVE}_{310}$ as an example, it is found that $1-2 \mathrm{wt} \%$ of polymer is necessary with $2 \mathrm{wt} \%$ of SNSs to induce ring assembly, and the optimal assembly temperature is $45^{\circ} \mathrm{C}$, at which the polymer is amphiphilic. Moreover, $\mathrm{EOVE}_{100}-b-\mathrm{MOVE}_{310}$ promotes the 1D assembly of larger SNSs $(30 \mathrm{~nm}$ in diameter) under otherwise optimal $\mathrm{pH}$, concentration and temperature conditions for the ring assembly of $15 \mathrm{~nm}$-SNSs, implicating a relationship between ring and $1 \mathrm{D}$ assembly modes. Although the mechanisms of ring assembly remain to be explored, this study demonstrates that the 'fusion' of SNSs with block copolymers obtained with the state-of-theart polymer chemistry will open new avenues in liquid-phase particle assembly.

\section{ACKNOWLEDGEMENTS}

This work was supported by a Grant-in-Aid for Scientific Research on the Innovative Areas: 'Fusion Materials' (Area no. 2206) from the Ministry of Education, Culture, Sports, Science and Technology (MEXT), Japan. A part of this work was conducted in Center for Nano Lithography \& Analysis, The University of Tokyo. S. Zhou is grateful for financial support from the China Scholarship Council (CSC) and the Global Center of Excellence for Mechanical Systems Innovation (GMSI, The University of Tokyo). We thank Professors Shokyoku Kanaoka and Arihiro Kanazawa (Osaka University) for valuable discussions.

1 Li, F., Josephson, D. P. \& Stein, A. Colloidal assembly: the road from particles to colloidal molecules and crystals. Angew. Chem. Int. Ed. 50, 360-388 (2011).

2 Földi, P., Kálmán, O., Benedict, M. G. \& Peeters, F. M. Networks of quantum nanorings: programmable spintronic devices. Nano Lett. 8, 2556-2558 (2008).

3 Li, S. P., Peyrade, D., Natali, M., Lebib, A., Chen, Y., Ebels, U., Buda, L. D. \& Ounadjela, K. Flux closure structures in cobalt rings. Phys. Rev. Lett. 86, 1102-1105 (2001)

4 Chang, W.-S., Slaughter, L. S., Khanal, B. P., Manna, P., Zubarev, E. R. \& Link, S. Onedimensional coupling of gold nanoparticle plasmons in self-assembled ring superstructures. Nano Lett. 9, 1152-1157 (2009)

5 Zhang, L., Si, H.-Y. \& Zhang, H.-L. Highly ordered fluorescent rings by "breath figures" on patterned substrates using polymer-free CdSe quantum dots. J. Mater. Chem. 18, 2660-2665 (2008).

6 Wei, A., Kasama, T. \& Dunin-Borkowski, R. E. Self-assembly and flux closure studies of magnetic nanoparticle rings. J. Mater. Chem. 21, 16686-16693 (2011).

7 Cai, Y., Li, Y., Nordlander, P. \& Cremer, P. S. Fabrication of elliptical nanorings with highly tunable and multiple plasmonic resonances. Nano Lett. 12, 4881-4888 (2012).

8 Shafi, K. V. P. M., Felner, I., Mastai, Y. \& Gedanken, A. Olympic ring formation from newly prepared barium hexaferrite nanoparticle suspension. J. Phys. Chem. B. 103, 3358-3360 (1999)

9 Cai, Y. \& Newby, B. Z. Marangoni flow-induced self-assembly of hexagonal and stripelike nanoparticle patterns. J. Am. Chem. Soc. 130, 6076-6077 (2008).

10 Yin, Y., Lu, Y., Gates, B. \& Xia, Y. Template-assisted self-assembly: a practical route to complex aggregates of monodispersed colloids with well-defined sizes, shapes, and structures. J. Am. Chem. Soc. 123, 8718-8729 (2001).

11 Chen, J., Liao, W.-W., Chen, X., Yang, T., Wark, S. E., Son, D. H., Batteas, J. D. \& Cremer, P. S. Evaporation-induced assembly of quantum dots into nanorings. ACS Nano 3, 173-180 (2009).

12 Darwich, S., Mougin, K., Vidal, L., Gnecco, E. \& Haidara, H. Nanobubble and nanodroplet template growth of particle nanorings versus nanoholes in drying nanofluids and polymer films. Nanoscale 3, 1211-1217 (2011).

13 Fujii, S., Kanaizuka, K., Toyabe, S., Kobayashi, K., Muneyuki, E. \& Haga, M. Fabrication and placement of a ring structure of nanoparticles by a laser-induced micronanobubble on a gold surface. Langmuir 27, 8605-8610 (2011).

14 Tripp, S. L., Pusztay, S. V., Ribbe, A. E. \& Wei, A. Self-assembly of cobalt nanoparticle rings. J. Am. Chem. Soc. 124, 7914-7915 (2002).

$15 \mathrm{Hu}$, M.-J., Lu, Y., Zhang, S., Guo, S.-R., Lin, B., Zhang, M. \& Yu, S.-H. High yield synthesis of bracelet-like hydrophilic $\mathrm{Ni}-\mathrm{Co}$ magnetic alloy flux-closure nanorings. J. Am. Chem. Soc. 130, 11606-11607 (2008).

16 Xiong, Y., Ye, J., Gu, X. \& Chen, Q.-W. Synthesis and assembly of magnetite nanocubes into flux-closure rings. J. Phys. Chem. C 111, 6998-7003 (2007).

17 Li, L., Wang, T., Zhang, L., Su, Z., Wang, C. \& Wang, R. Selected-control synthesis of monodisperse $\mathrm{Fe}_{3} \mathrm{O}_{4} @ \mathrm{C}$ core-shell spheres, chains, and rings as high-performance anode materials for lithium-ion batteries. Chem. Eur. J. 18, 11417-11422 (2012).

18 Tripp, S. L., Dunin-Borkowski, R. E. \& Wei, A. Flux closure in self-assembled cobalt nanoparticle rings. Angew. Chem. Int. Ed. 42, 5591-5593 (2003).

$19 \mathrm{Kim}$, J.-H. \& Kim, J.-W. Simultaneously controlled directionality and valency on a watersoluble gold nanoparticle precursor for aqueous-phase anisotropic self-assembly. Langmuir 26, 18634-18638 (2010).

20 Watanabe-Tamaki, R., Ishikawa, A., Tanaka, T., Zako, T. \& Maeda, M. DNA-templating mass production of gold trimer rings for optical metamaterials. J. Phys. Chem. C 116 15028-15033 (2012)

21 Zahr, O. K. \& Blum, A. S. Solution phase gold nanorings on a viral protein template. Nano Lett. 12, 629-633 (2012).

22 Yokoi, T., Sakamoto, Y., Terasaki, O., Kubota, Y., Okubo, T. \& Tatsumi, T. Periodic arrangement of silica nanospheres assisted by amino acids. J. Am. Chem. Soc. 128 13664-13665 (2006)

23 Fukao, M., Sugawara, A., Shimojima, A., Fan, W., Arunagirinathan, M. A., Tsapatsis, M. \& Okubo, T. One-dimensional assembly of silica nanospheres mediated by block copolymer in liquid phase. J. Am. Chem. Soc. 131, 16344-16345 (2009).

24 Zhou, S., Sakamoto, T., Wang, J., Sugawara-Narutaki, A., Shimojima, A. \& Okubo, T. One-dimensional assembly of silica nanospheres: effects of nonionic block copolymers. Langmuir 28, 13181-13188 (2012).

25 Israelachvili, J. N. Intermolecular and Surface Forces, 3rd edn (Adademic Press, Waltham, MA, USA, 2011). 
26 Larson-Smith, K. \& Pozzo, D. C. Scalable synthesis of self-assembling nanoparticle clusters based on controlled steric interactions. Soft Matter 7, 5339-5347 (2011).

27 Zanella, M., Bertoni, G., Franchini, I. R., Brescia, R., Baranov, D. \& Manna, L. Assembly of shape-controlled nanocrystals by depletion attraction. Chem. Commun. 47, 203-205 (2011).

28 Ciszek, J. W., Huang, L., Tsonchev, S., Wang, Y., Shull, K. R., Ratner, M. A. Schatz, G. C. \& Mirkin, C. A. Assembly of nanorods into designer superstructures: the role of templating, capillary forces, adhesion, and polymer hydration. ACS Nano 4, 259-266 (2010).

29 Aoshima, S., Oda, H. \& Kobayashi, E. Synthesis of thermally-induced phase separating polymer with well-defined polymer structure by living cationic polymerization. 1. synthesis of poly(vinyl ethers) with oxyethylene units in the pendant and its phase separation behavior in aqueous solution. J. Polym. Sci., Part A: Polym. Chem. 30, 2407-2413 (1992).
30 Sugihara, S., Kanaoka, S. \& Aoshima, S. Double thermosensitive diblock of vinyl ethers with pendant oxyethylene groups: unique physical gelation. Macromolecules 38, 1919-1927 (2005).

31 Aoshima, S. \& Higashimura, T. Living cationic polymerization of vinyl monomers by organoaluminum halides. 3. living polymerization of isobutyl vinyl ether by $\mathrm{EtAlCl}_{2}$ in the presence of ester additives. Macromolecules 22, 1009-1013 (1989).

32 Sun, K. \& Raghavan, S. R. Thermogelling aqueous fluids containing low concentrations of pluronic F127 and laponite nanoparticles. Langmuir 26, 8015-8020 (2010).

33 Iler, R. K. The Chemistry of Silica (Wiley, New York, 1979).

34 Surve, M., Pryamitsyn, V. \& Ganesan, V. Nanoparticles in solutions of adsorbing polymers: pair interactions, percolation, and phase behavior. Langmuir 22 969-981 (2006). 